\title{
A Renovação Carismática Católica \\ Uma igreja dentro da Igreja?
}

\author{
Cecília L. Mariz'
}

O discurso sobre religiosidade contemporânea tem enfatizado a prioridade da experiência sobre a instituição ou organização religiosa. Em geral, os fiéis se referem apenas à mensagem ou a uma experiência mística especial para explicar sua atração e perseverança em participar de um determinado grupo ou movimento religioso. Nesse tipo de relato quase não se encontram menções ao papel da organização. No entanto, não são apenas os fiéis que subestimam a organização religiosa, também um setor importante da própria literatura em ciências sociais especializada em religião tem enfatizado pouco essa dimensão do religioso no mundo atual. Essa literatura tem chamado atenção para um processo de autonomização dos indivíduos em relação às instituições religiosas, ou seja, o processo de "desinstitucionalização" ou "desregulação religiosa", como diria Hervieu-Léger (1999). Ao se enfatizar

\footnotetext{
${ }^{1}$ Doutora em Sociologia da Cultura e da Religião pela Boston University, Estados Unidos, professora na Universidade do Estado do Rio de Janeiro; autora, entre outros, de Coping with poverty: Pentecostals and Base Communities in Brazil (Temple University Press, 1994). Endereço: cemariz@alternex.com.br.
} 
os aspectos antiinstitucionais e não burocratizados da religião atual, esquece-se que a transmissão e reprodução de experiências coletivas apenas podem ocorrer porque existem organizações sociais. A vida social, por sua própria dinâmica, se organiza para poder sobreviver. Mesmo que a religiosidade contemporânea pareça ser para o fiel algo cada vez mais emocional, experiencial e espontâneo, o analista não pode negligenciar o fato de que graças a estruturas organizativas específicas, experiências desse tipo podem se manter e se expandir na vida social. Weber (1991, p. 161) já notava que nenhum carisma permanece nem se reproduz sem um processo de rotinização. A rotinização implica a institucionalização e burocratização, seja essa racional ou tradicional ou mistura de ambas (Weber, 1991, p. 162). Somente assim experiências e mensagens se transmitem para além das relações face a face e através das gerações.

Dessa forma, o discurso sobre a desinstitucionalização e desregulamentação do religioso estaria dando conta apenas parcialmente da realidade. Está focado unicamente sobre o fiel e suas buscas, ou seja, prioriza a análise do fenômeno a partir do ponto de vista do sujeito ou do consumidor religioso, e negligencia a análise do papel dos produtores ou detentores dos bens religiosos, para usar a terminologia da "teoria do mercado religioso". Novas formas de viver a religião implicam novas formas de organização e/ou transformações nas instituições tradicionais, mas não a sua negação ou simples desaparecimento.

Diferentes movimentos ou grupos religiosos, tanto aqueles com perfil do que se costuma chamar de Nova Era, como os grupos pentecostais e carismáticos, cuja base é uma experiência mística, têm desenvolvido complexas organizações de amplitude internacional. Além disso, esses grupos participam muitas vezes de redes que se constituem em novas organizações interreligiosas que coordenam a relação - encontros e trocas - entre distintos movimentos, grupos, igrejas. Por outro lado, podem se agregar também a um outro tipo de organizações religiosas que desenvolvem interfaces com outras esferas sociais, sejam essas de serviços de saúde, de comunicação, educativas, artísticas, políticas, financeiras, comerciais, familiares etc. Desse modo, organizações propriamente religiosas podem se complexificar quando por vezes se misturam com instâncias organizativas de atividades relacionadas a outras esferas sociais, criando órgãos com fundamento religioso mas sendo também centros terapêuticos, rádios, editoras, televisões, e pequenas indústrias, lojas, comércios religiosos, escolas, entre outros.

Por todos esses motivos, é muito importante estudar a forma como um grupo ou movimento religioso se organiza. Análises comparativas entre movimentos e/ou grupos religiosos distintos revelam que do tipo de organi- 
zação depende não apenas a amplitude da divulgação da mensagem, mas também o poder de manter seus fiéis engajados e perseverantes, e ainda a capacidade do grupo de lidar com a diversidade e possíveis tensões que levam a dissidências ou impedem o crescimento do movimento (Mariano, $2001){ }^{2}$ De fato, o tipo de organização de um grupo pode ajudar, ou não, a expansão de suas fronteiras. Há formas de organização que auxiliam o trabalho missionário, ampliam a divulgação da mensagem. Dinâmicas organizacionais permitem a criação de novos grupos para seguir as orientações gerais do movimento mais amplo. Algumas organizações são mais eficientes do que outras em apoiar o novo adepto, oferecendo mecanismos e suportes que o incentivem a continuar no grupo. Há organizações que favorecem a união do grupo e ajudam sua auto-reprodução material. A ausência de estruturas organizacionais claras e eficientes para a gestão de bens materiais do grupo poderá levar a uma má administração dos recursos e ainda a conflitos internos e até a sua divisão. Também a forma como um grupo lida com outros grupos ou movimentos religiosos e com a sociedade mais ampla será afetada pela organização adotada. Portanto, da organização depende não apenas a expansão desse grupo, mas mesmo sua própria sobrevivência.

Um caso paradigmático da importância da organização para a sobrevivência de um tipo de carisma é o da Igreja Católica. Uma das explicações para a sobrevivência dessa igreja sob uma liderança unificada por tantos séculos se encontra em sua organização caracterizada pela capacidade de controlar os desvios e manter grupos divergentes juntos. ${ }^{3}$ A importância dada à hierarquia e à autoridade fez com que as dissidências e rupturas que ocorreram através da história fossem relativamente pouco numerosas em relação aos conflitos e tensões que já dividiram essa instituição. Essa capacidade integrativa da organização católica se revela forte quando se compara essa igreja com as protestantes, que sofrem freqüentemente cisões e se subdividem. O protestantismo, por sua proposta original, não tem estrutura organizativa que incorpore divergências. Quando Lutero, como disse Marx (s. d., p. 127), "acabou a fé na autoridade, porque restaurou a autoridade da fé”, ele rompeu com o modelo organizacional católico.

As estruturas organizacionais das diversas igrejas protestantes podem variar amplamente entre si, mas se assemelham por serem bem mais suscetí-

\footnotetext{
${ }^{2}$ Ricardo Mariano (2001) mostra como organizações religiosas centralizadas e empresariais podem explicar o sucesso de determinadas denominações evangélicas no Brasil.

${ }^{3}$ As análises de Gramsci sobre a Igreja Católica destacam a importância de sua organização para entender sua força ideológica e política e sua persistência através da história (Gramsci apud Staccone, 1989).
} 
veis a rupturas do que tem sido a estrutura da Igreja Católica. O próprio movimento pentecostal nas igrejas protestantes foi responsável pelo surgimento de dissidências que levaram à criação de novas denominações religiosas. O mesmo não ocorreu com o pentecostalismo católico, que se transformou no Movimento de Renovação Carismática. O crescimento desse movimento tem, pelo contrário, contribuído para o fortalecimento do espaço institucional da Igreja Católica. Para entender esse fenômeno, é importante analisar não apenas a organização do $\mathrm{MRCC}$, mas como a estrutura mais ampla da Igreja Católica conduziu a Renovação a adotar um tipo específico de organização.

O objetivo do presente artigo não será descrever a organização do MRCC, mas propor a hipótese de que organização mais ampla da Igreja condicionou a RCC a adotar um modelo organizacional tal que limitou e conteve algumas de suas propostas centrais. Se por um lado, a burocracia católica permite uma relativa autonomia de suas subestruturas organizacionais, e é assim no caso do MRCC, por outro, essa autonomia pode marginalizar essas subestruturas. É fato que, enquanto subestrutura com relativa autonomia, a RCC adotou um estilo organizacional próprio, que a distingue das demais instâncias católicas, que muito contribuiu para seu sucesso e crescimento. No entanto, esse processo de integração relativa, que levou a RCC a se conceber como movimento de leigos, implicou a redefinição e redução de suas metas. Esse artigo tenta mostrar que a meta Renovação Carismática era e é mudar a Igreja como um todo: propor uma nova forma de ser Igreja tanto para os leigos quanto para o clero. A dinâmica da organização maior da Igreja, contudo, não comporta uma única forma de ser Igreja. Analisa-se aqui como se ofereceram estratégias para que esse projeto (como provavelmente ocorreu com outros diversos projetos anteriores de ser igreja) se conformasse sobrevivendo dentro da Igreja ao manter uma relativa autonomia organizativa, sem abandonar a organização maior. A organização do tipo do chamado "movimento religioso" (na acepção que essa expressão possui dentro da organização da Igreja Católica ${ }^{4}$ ) não teria sido uma opção da RCC, mas seria, na dada conjuntura, o único modo encontrado para se integrar à organização mais ampla da Igreja.

\footnotetext{
${ }^{4}$ No universo católico chama-se de "movimento religioso" um tipo específico de organização que se insere na estrutura mais ampla da Igreja, mas sendo unificado, administrado internacionalmente e independente do clero local. Em geral, atua ou se dirige apenas a camadas ou setores específicos da Igreja ou da sociedade. Na maioria das vezes tem práticas e estilos uniformes e muitas vezes possui um fundador reconhecido. Esse conceito é usado por diversos autores, como Oliveira (1997), Souza (2000), Boff (2000), Carranza (2000).
} 
Argumenta-se aqui que a organização da Igreja Católica apresenta dispositivos que permitem uma diversidade controlada. Criando espaço para o desenvolvimento de subestruturas, subgrupos, ou até comunidades autônomas, sem deixar de reforçar a importância da identidade unificada dentro da organização maior, a Igreja tem conseguido manter um diálogo e evitar rupturas. Impede assim que as propostas novas de viver a fé se tornem denominações e/ou seitas (no sentido dado por Tröeltsch) fora da Igreja. Teria sido através desses dispositivos que se instalaram ordens religiosas, outras comunidades diversas e movimentos religiosos. Argumenta-se que esse é o dispositivo que permitiu a incorporação da RCC, evitando maiores tensões. Ainda mais, argumenta-se que esse dispositivo também é adotado pela própria RCC, que através dele é capaz de incorporar dentro de sua própria organização grupos de oração e comunidades de aliança e vida que conservam uma grande diversidade de estilos, de discursos, e relativa autonomia.

\section{Organização como "movimento" versus "ser igreja"}

Apesar de atualmente a RCC estar organizada como "movimento" e ser assim considerada pela própria Igreja, esse não era, nem é, o seu projeto, como fica claro nas declarações de seus líderes. A Renovação não quer ser um movimento a mais dentro da Igreja, mas sim transformar a própria Igreja: ser uma nova Igreja. Dessa forma estariam compartindo ou competindo com as Comunidades Eclesiais de Base, que também se declaram "um novo jeito de ser Igreja", ou "novos jeitos de ser Igreja", como prefere Luiz Alberto Gómez de Souza (2000, p. 104).

Tal como a Teologia da Libertação, o projeto da Renovação Carismática é mudar a forma de viver o catolicismo de toda a Igreja, e não apenas de alguns setores. No entanto, como salientam diversos autores, entre esses Prandi (1997, p. 34), Oliveira (1997) e Souza (2000), o tipo de organização do MRCC é bem diferente daquele das CEBs e das pastorais sociais inspiradas pela Teologia da Libertação. Oliveira (1997), inclusive, nega a possibilidade de se fazer qualquer comparação entre CEBs e grupos de oração. Para ele, as CEBs seriam uma nova forma de organizar a Igreja, já os grupos de oração carismática fariam parte de um "movimento" nos moldes organizacionais dos demais já existentes na Igreja Católica. Luiz Alberto Gómez de Souza (2000, p. 104) identifica também uma especificidade do estilo organizacional das CEBs quando comparado com o de outros grupos e "movimentos católicos". Destaca entre as CEBs a ausência de centralização: 
Em lugar dos movimentos centralizados com direção nacional e mesmo internacional (...) como foi inclusive o caso da Ação Católica (...), as CEBs são, sobretudo uma rede de experiências eclesiais diversificadas, diferentes entre si, não seguindo uma receita prefixada, mas respondendo desafios das realidades sociais e eclesiais específicas.

Uma das características do "movimento" seria possuir uma organização nacional e internacional e ser centralizado. Como atualmente possui uma estrutura internacional, a RCC se assemelharia mais aos "movimentos" nesse sentido. No entanto, vários líderes da RCC negam que sejam "movimento". Ainda nos primeiros anos da RCC aqui no Brasil, em 1973, Brenda Carranza (2000, p. 37) comenta que em uma reunião na CNBB "foi definida pela primeira vez em solo brasileiro a RCC "como um novo modo de ser Igreja.'” De acordo com o Comunicado Mensal da CNBB (de 5/6/1973 p. 654-5 apud Carranza 2000, p. 37), o padre Haroldo Rahm, um dos pais fundadores da RCC no Brasil, declara ainda que a Renovação "não se trata de uma organização ou de movimento em sentido restrito". Brenda Carranza (2000, p. 38) também cita declaração similar do padre Eduardo Dougherty, o outro fundador da Renovação brasileira, feita em 1977, na qual rejeita a etiqueta de "movimento", explicando que "o movimento é para um grupo, enquanto uma renovação litúrgica, bíblica e carismática é para todo mundo". A mesma linha de argumento segue o padre McDonnel, líder da RCC internacional, citado por D. Cipriano Chagas (1976 apud Carranza, 2000, p. 38), quando fala que a Renovação quer ser "uma Igreja renovada carismaticamente, que não tenha necessidade de um movimento específico".

Os líderes leigos também confirmam essa posição, como se nota pela declaração do ex-presidente do Conselho Nacional da RCC no Brasil, citado por Júlia Miranda (1999, p. 52): "nós da Renovação nem nos consideramos um movimento leigo a mais da Igreja (...) nós nos consideramos e queremos ser a própria Igreja Católica em renovação". Similar foi também a declaração de outro líder leigo, o ex-presidente do International Catholic Charismatic Office (órgão sobre o qual se falará mais adiante), Charles Whitehead, em entrevista dada em Melbourne na Austrália em 26 de janeiro de 1999, divulgada pelo site da Renovação Carismática da Arquidiocese de Melbourne.

Charles Whitehead, que na época da entrevista era presidente do National Service Commitee (Comitê Nacional de Serviço) da RCC na Inglaterra, se queixa da concepção da Renovação como movimento. Quando questionado sobre como gostaria de ver a RCC nos próximos dez anos, afirma que gostaria que ela estivesse mais presente em toda a vida da Igreja, seja nas paróquias, dioceses, seminários. Comenta, então: 
Nós fomos marginalizados em certa medida como um tipo de movimento para entusiasta, ou outra coisa do gênero. Certamente não por culpa do Santo Padre, pois ele tem promovido os movimentos, incluindo a RCC.

Ao se declararem uma nova forma de ser igreja, esses líderes estão, ao menos ao nível do discurso, negando um tipo específico de organização social paralela que parece caracterizar esses chamados "movimentos religiosos" dentro da Igreja Católica, e estão declarando que querem reorganizar toda a Igreja segundo seu novo projeto. A rejeição da etiqueta movimento expressa, tal como no projeto das CEBs e dos católicos da Teologia da Libertação, o desejo de abarcar toda a Igreja e não ser algo marginal com uma organização paralela. Por ambas tendências terem projetos encompassadores que visam abranger toda a Igreja, entende-se porque a Renovação e as CEBs se percebam como forças antagônicas. A dinâmica organizacional centralizada e ao mesmo tempo plural da Igreja Católica tem conseguido, no entanto, que movimentos distintos e até potencialmente opostos possam conviver e eventualmente dialogar.

\section{Carisma versus burocratização}

Há sobre a Renovação, e também dentro da Renovação, um discurso não apenas contra a organização em termos de movimento, mas contra qualquer organização ou burocratização em geral. Esse discurso aparece assim tanto entre analistas do movimento, como entre seus líderes. Baseada em uma declaração do próprio padre Haroldo Rahm, Carranza (2000, p. 41) conclui que a burocratização foi a responsável pelo afastamento da RCC desse padre, que foi um de seus fundadores no Brasil. A própria Brenda Carranza vê a organização em si como uma ameaça ao carisma, e mesmo como o começo do fim da proposta carismática. É ela quem comenta: "estruturar o carisma foi o dilema que a RCC precisou resolver e teve seu preço (...) organizar implicou matar a dimensão carismática do incipiente movimento" (Carranza, 2000, p. 40).

A organização ou burocracia parece ser vista como algo negativo. No entanto, para a mensagem do carisma sobreviver vai ser preciso a burocracia. Não é a burocracia que mata o carisma, esse morreria de um jeito ou de outro. A burocracia tenta ampliar através do tempo e do espaço os elementos inovadores trazidos pelo carisma. Dessa forma, o dilema que identifica Brenda Carranza do MRCC diante de sua burocratização não é um problema específico desse movimento, nem se pode dizer que a burocratização 
implica perda de carisma. Aqui é importante lembrar a contribuição de Weber sobre a questão.

Segundo Weber (1991), o carisma surge como força desreguladora, contestadora. O profeta ou líder carismático ou comunidade carismática questiona as regras existentes - desregula. No entanto, a experiência carismática é por sua natureza efêmera, passageira. Para que os valores e princípios despertos por essa experiência se mantenham, surge uma nova regulação: novas regras são propostas. A dinâmica histórica e social fará surgir novas regras que constituem a institucionalização do carisma. Se isso não ocorre, o carisma desaparece. Como já foi mencionado no início do texto, Weber (1991, p. 161) analisa esse processo quando discute a rotinização do carisma, que ocorre tanto em movimentos religiosos como políticos.

Embora se refira à oposição entre instituição e carisma, Weber não responsabiliza a primeira pelo arrefecimento do segundo. Já que o carisma é por sua natureza volátil e desaparece com o desaparecimento de sua fonte inicial. A rotinização vai necessariamente ocorrer. Há um imperativo organizacional: organize-se ou desapareça.

Como qualquer movimento social que cresce para além das relações face a face, a RCC se viu diante da necessidade de desenvolver uma burocracia, ou seja, de se organizar para poder se administrar. O surgimento dessa organização, apesar de sua base carismática com a experiência dos dons, não é assim a questão que se coloca aqui, já que se considera inevitável o desenvolvimento de um tipo qualquer de organização para a sobrevivência da experiência. O que se questiona é por que a RCC se organizou em termos de "movimento", nos moldes de outros já existentes na Igreja Católica, moldes que eram e são rejeitados pela sua própria liderança. Por que adotou uma organização internacional centralizada? Por que desenvolveu um tipo de organização que parece ser marginal à própria Igreja, como se queixa sua liderança (ver as declarações já citadas de Charles Whitehead)?

\section{A organização internacional como "movimento" e a integração na estrutura da igreja}

Como a Renovação chegou ao Brasil muito cedo, logo depois de seu surgimento nos EUA, a organização no Brasil se deu de forma simultânea à organização do movimento em termos internacionais. Em 1973, no mesmo ano que houve o primeiro congresso nacional no Brasil, em Itaici, se realizou também a primeira conferência internacional na Itália em Grottaferrata (Boff, 2000). 
Da mesma forma como ocorreu no Brasil, onde organização da RCC se deu através de seus congressos nacionais (Carranza, 2000, p. 40), também a organização do movimento em nível internacional foi se estabelecendo de forma paulatina, ganhando forma e se consolidando através dos congressos internacionais. Portanto, diferentemente dos chamados "movimentos religiosos" a que se tem referido, tais como o movimento Focolare e Cursilhos de Cristandade, o MRCC não chegou ao país já organizado. Mas, pelo contrário, como já mencionado, a organização nacional e a internacional se desenvolveram de forma simultânea. Quando o MRCC chegou ao Brasil ainda não havia nenhum órgão ou instância que centralizasse o movimento como tal, nem que enviasse seus representantes. O International Catholic Charismatic Renewal Service (ICCRS) foi criado bem posteriormente.

Na homepage do MRCC há muitas informações sobre o ICCRS. Lá se encontra a sua história redigida por Brian Smith, um australiano líder internacional da RCC. Segundo a narrativa de Smith, até 1972, quando foi criado o ICO ou International Communication Office (Escritório de Comunicação Internacional) com objetivo de ajudar na comunicação entre grupos carismáticos de países distintos, não havia órgão algum em nível internacional. $\mathrm{Na}$ época de sua criação, o ICO se localizava em Ann Arbor, Michigan, nos EUA, e se reduzia à mesa de trabalho do líder carismático Ralph Martin.

O ICO queria contribuir para a Renovação publicando um boletim informativo e um catálogo internacional de grupos de oração. Ainda buscava fornecer material bibliográfico e fitas de áudio e vídeo e organizar encontros internacionais. Assim, em cerca de um ano de existência, em outubro de 1973, o ICO organiza a Conferência Internacional de líderes da Renovação realizada em Grottaferrata, Itália. Estavam presentes nessa conferência 120 líderes da renovação. Nesse momento havia apenas 6 anos que a Renovação tinha surgido e era seu primeiro encontro internacional, mas o Papa Paulo VI já recebeu seus líderes (Boff, 2000, p. 39).

De Ann Arbor, no Michigan, o ICO muda-se em 1974 para Bruxelas, Bélgica, onde vivia o diretor responsável (Ralph Martin). Em 1975, já conseguiu organizar o "Primeiro Congresso Internacional" em Roma, que atraiu 10 mil participantes (Boff, 2000, p. 40). No segundo semestre de 1977, a partir de uma consulta a 110 representantes de 60 países, decidiu-se formar um comitê internacional para supervisionar o trabalho do ICO. Em 1981, o ICO passa a se chamar ICCRO (International Catholic Charismatic Renewal Office ou Escritório Internacional da Renovação Carismática Católica), que se muda para Roma. 
O desejo de ter um reconhecimento pontifício levou a busca de maior institucionalização do movimento através da aprovação de um estatuto. Segundo conta o site do MRCC, membros dos ICCRO elaboraram esses estatutos. Após serem submetidos à análise de canonistas e teólogos do Vaticano e tendo "incorporado as devidas observações, foram aprovados em 8 de Julho de 1993, com o título: 'Estatutos do Serviço Internacional da Renovação Carismática Católica“”. Assim naquele ano o ICCRO mudou o nome para ICCRS - Office (Escritório) foi substituído por Service (Serviço) por julgarem o último termo mais adequado que o primeiro à função que desempenhava. ${ }^{5}$ Ainda de acordo com a narração do site:

em 14 de setembro de 1993 (...) a Santa Sé, através do Pontifício Conselho para os Leigos, sob a presidência do Cardeal Pirônio, entregou pessoalmente aos membros do Conselho Internacional o "Decreto" reconhecendo o ICCRS (Serviço Internacional da Renovação Carismática Católica) como: "um corpo para a promoção da Renovação carismática católica, com uma personalidade jurídica", segundo o Cânone 116 do Código de Direito Canónico (Pontificium Consilium pro Laicis (1565/93 AIC-73).

Para o ex-presidente do ICCRS, Charles Whitehead, os estatutos marcam o reconhecimento oficial do ICCRS pelo Pontificium Consilium pro Laicis (Pontifício Conselho para os Leigos) como o representante da RCC. ${ }^{6}$ Para ele, com esse reconhecimento se renova a confiança entre esses órgãos. De certa forma, observa-se aí que a Igreja, como a organização maior e inclusiva, condicionou o diálogo com o RCC ao desenvolvimento de um tipo de organização específica. Os "Estatutos", e o status oficial adquirido através dele, são considerados fundamentais para integrar a RCC dentro da organização mais ampla da Igreja Católica. No entanto, o conteúdo desses "Estatutos", como se verá em seu preâmbulo, além da exigência de que fossem aprovados pelo "Conselho para os Leigos", de certa forma, reduz a Renovação a um "movimento" de leigos. Encontra-se no preâmbulo desses estatutos, como se pode ver no seu site, a definição da Renovação como um "movimento", a despeito do que dizem os líderes sobre isso. Ela é então definida como:

um movimento mundial, mas não uniforme, nem unificado. Não tem um fundador particular, nem um grupo de fundadores como muitos outros movimentos. Não tem listas de membros participantes.

Embora se especifique que é distinta do modelo de "movimentos", que tiveram fundador e que são unificados, não se foge à definição de que a

\footnotetext{
${ }^{5}$ A justificativa para essa mudança de nome se encontra nesse mesmo site, quando se afirma que "mais do que como um governo, a liderança se caracteriza como um oferecimento de serviço para aqueles que o desejam".

${ }^{6}$ Depoimento divulgado na homepage sobre ICCRS.
} 
RCC é um movimento. Dessa forma o diálogo com as instâncias organizativas da Igreja concorreu para que ela se conformasse a se conceber como tal.

O MRCC é, então, um movimento de leigos representado por um organismo internacional: o ICCRS. Esse é formado por conselho diretor presidido por leigos. O atual presidente é Allan Panozza, da Austrália, e o vicepresidente é Matteo Calisi, da Itália. Participam ainda desse conselho 14 representantes, dentre esses estão os que representam os cinco continentes, além de representante de ministérios e comunidades. Há três orientadores espirituais (padres) que participam também do conselho. No site do movimento há uma foto e pequena biografia de cada um dos participantes, além de seu $e$-mail para contato. Os representantes são escolhidos por um prazo de 2 anos. Mas muitas vezes continuam em seus cargos por mais de um mandato. Seus nomes têm que ser aprovados por autoridades eclesiásticas.

Entre as funções desempenhadas pelo ICCRS estão: orientar a RCC em nível internacional, apoiar as iniciativas dos Conselhos Nacionais de cada país, promover encontros e congressos, divulgar boletim informativo. O ICCRS dispõe de recursos doados por membros. Com esses recursos, entre outras coisas, financia a viagem de delegados de países em desenvolvimento e também apóia financeiramente iniciativas de grupos desses países. Assim, ao se analisar a Renovação a partir da sua organização internacional e atividades de seus organismos internacionais é-se levado a crer numa homogeneidade do movimento. No entanto, quando se parte da base dessa organização, dos grupos de oração, que são as instâncias primeiras que se formam em torno da experiência com os dons do Espírito Santo, ou então das comunidades, sejam essas de vida ou de aliança, tem-se uma visão diferente do movimento, mais complexa, mais plural e menos unificada.

\section{Grupos de Oração e Comunidades de Aliança e de Vida}

No extremo oposto do ICCRS, ou seja, na base do movimento encontrase a sua estrutura mais simples e básica formada pela rede de grupos de oração. Esses grupos constituem as células do movimento e a sua estrutura mais flexível. Todo participante da RCC está envolvido em um grupo de oração.

Pesquisas com observações participantes em grupos de oração no Rio de Janeiro apontam para a espontaneidade do seu funcionamento. ${ }^{7}$ Também

\footnotetext{
${ }^{7}$ Além das pesquisas já publicadas (Mariz, 2001 e Mariz e Machado, 1994), refiro-me aqui à pesquisa ainda em conclusão que se realiza com o apoio do CNPq ("Os rumos atuais do cato-
} 
revelam que a definição da liderança se faz de maneira muito informal. Tornam-se líderes aqueles que se destacam no grupo por sua devoção ou através dos "dons" e que se sentem escolhidos pelo Espírito Santo. Há um consenso entre os participantes de que a liderança e o roteiro para as reuniões devem ser definidos através da iluminação do Espírito Santo, ou seja, pela força do carisma. Embora a interpretação das revelações do carisma também possam obedecer certos padrões, esses padrões são flexíveis e podem variar de um local para outro. A institucionalização nesse setor do movimento pode ocorrer em grau e forma diversos.

Relatos da origem dos grupos no Rio de Janeiro, obtidos nas pesquisas acima referidas, mostram que esses, em geral, surgem a partir de iniciativas de leigos. Em muitos casos estudados, especialmente em paróquias em áreas de baixa renda, a idéia de organizar um grupo de oração enfrentou inicialmente uma resistência do pároco. Muitas vezes o grupo de oração se forma sem nenhuma vinculação com o Comitê Nacional ou equipes diocesanas do MRCC. Uma aproximação posterior se dá, e é aí que se propõe um Seminário de Vida no Espírito. Esse Seminário tende a integrar os participantes do novo grupo ao restante da estrutura do movimento.

Outra instância bem mais complexa do que o grupo de oração, mas também possuidora de dinâmica própria e relativa autonomia em relação ao resto do movimento, são as comunidades de aliança e de vida. Júlia Miranda (1999) e Brenda Carranza (2000) já explicaram em seus trabalhos o que são essas comunidades e relatam as histórias e perfis de várias delas no Brasil. ${ }^{8}$ Algumas comunidades de vida e de aliança crescem tanto que se expandem geograficamente por mais de um Estado da federação. A comunidade de vida, tal como uma ordem religiosa, pode ter suas regras próprias e se autosustenta em termos materiais. Na maioria das vezes é inspirada por um líder (ou líderes) carismático especial, que tanto pode ser sacerdote ou leigo.

Júlia Miranda (1999, p. 54) descreve especificamente o caso da comunidade de vida Shalom, a primeira fundada no Estado do Ceará, mas que atualmente já tem casa até no Rio de Janeiro. Essa comunidade foi criada por

licismo na base"), ao artigo de Sílvia Fernandes (1996) e às pesquisas que resultaram nas monografias de conclusão de curso de Ciências Sociais da UERJ de autoria de Roberto Nascimento e de Francisco Cleve Diniz.

${ }^{8}$ As comunidades de vida também são descritas na literatura internacional sobre RCC. Como exemplo citamos os trabalhos de Martine Cohen (1990 e 1997). Cohen (1997, p. 136) considera essas comunidades "une nouvelle manière d'acclimater des traits sectaires au sein de l'Église"'. 
um jovem e uma senhora casada ${ }^{9}$. Ambos, segundo Miranda, são fortes lideranças e referências constantes no MRCC em Fortaleza. Esse líder, que se chama Moysés (adota-se aqui a grafia do nome tal como consta no site da comunidade), teria tido depois contato com o padre Jonas Abib, o fundador da comunidade Canção Nova ${ }^{10}$, em Cachoeira Paulista, São Paulo. Depois desse encontro teria recebido inspiração divina para elaborar as regras da comunidade Shalom.

O surgimento e o estabelecimento das comunidades de vida como parte da organização do MRCC indicam que a organização desse movimento traz para dentro de si dispositivos similares aos da organização da Igreja Católica. Dessa forma, tal como a estrutura da instituição mais abrangente, a organização do MRCC dá espaço para lideranças carismáticas diversas criarem grupos com carismas e estilos religiosos distintos, adotando, inclusive, regras de vida específicas. A variedade dessas comunidades, somada à dos grupos de oração, traz uma pluralidade interna muito grande ao MRCC. Nisso esse movimento se diferencia dos demais "movimentos" da Igreja.

Outro aspecto que diferencia o MRCC é sua abrangência. Além dos grupos e comunidades de vida, há uma gama imensa de sub-organizações e projetos dentro desse movimento. Embora seja definida como movimento de leigos (estando inclusive subordinada ao Pontifício Conselho para os Leigos, como foi referido acima), nota-se que a Renovação integra muitos representantes do clero. É forte a presença desse na organização do MRCC e também no seu processo de expansão (Carranza, 2000). Tão ampla e complexa tem sido a organização do MRCC que esse passa a ser criticado por isso, como se mostrará a seguir.

\section{Abrangência e paralelismo da organização do MRCC: uma igreja dentro da Igreja}

Brenda Carranza (2000, p. 62) descreve a organização do MRCC como "uma imensa teia de projetos, atividades, estruturas burocráticas de ligações nacionais e internacionais". De fato a organização da RCC no Brasil e no mundo é hoje ampla, complexa, plural e tem chamado a atenção de diversos

\footnotetext{
${ }^{9}$ Júlia Miranda cita o nome de Moisés e Estela. Embora haja concordância que seja Moysés (a grafia que aparece lá é essa), a homepage da comunidade Shalom informa que a co-fundadora se chama Maria Emmir.

${ }^{10}$ Para mais informações sobre a Comunidade Canção Nova e o Padre Jonas Abib, ver o livro de Brenda Carranza (2000) e a recente dissertação de mestrado de Eliane Martins Oliveira (2003).
} 
autores que estudam o movimento no Brasil, tais como Brenda Carranza (2000), Ari Pedro Oro (1996), Reginaldo Prandi (1997, p. 34-37), Júlia Miranda (1999), entre outros. Em seus trabalhos esses autores já enumeraram as instâncias organizativas internacionais e nacionais, secretarias, projetos que se assomam à rede de grupos de oração e comunidades de aliança e de vida. Todo esse conjunto de grupos é responsável em diferente grau e de forma distinta pela realização de reuniões diversas, tais como Seminários de Vida no Espírito, Cenáculos e outros encontros, e ainda ações missionárias e sociais. Além disso, algumas comunidades, por seu lado, organizaram serviços de assistência social, creches, escolas, ou emissoras de rádio, de televisão, editoras etc., ampliando assim a estrutura organizacional que se relaciona à Renovação.

A dimensão e a força da organização do MRCC também têm chamado a atenção da hierarquia da própria Igreja Católica. Alguns setores dessa hierarquia se revelam preocupados com o que lhes parece ser a criação de estruturas paralelas de poder por parte desse movimento. Como nos lembra Ari Oro (1996, p. 115), a CNBB, através do documento "Orientações pastorais sobre a Renovação Carismática Católica", alerta esse movimento para que procure evitar "qualquer paralelismo" e que busque se integrar "na pastoral orgânica". Ari Pedro Oro destaca ainda que a CNBB chama atenção para a necessidade do controle diocesano tanto dos projetos que "só poderão ser implantados em sintonia com os organismos pastorais da Diocese" como dos convites de pessoas para dar conferências, que não devem prescindir da "devida anuência do bispo diocesano ou de quem for por ele indicado" (Oro, 1996, p. 115).

A crítica a esse paralelismo também aparece nas análises de intelectuais e líderes católicos. Em uma análise de conjuntura religiosa elaborada pela equipe do Ibrades (Santos, 1996, p. 29), comenta-se que os opositores da Renovação, sejam leigos ou clérigos, a criticam, entre outros motivos, por sua "autonomia bastante grande em relação à autoridade eclesiástica". Nessa linha de argumentação, Branda Carranza (2000, p. 61), comentando a complexidade e autonomia da RCC, afirma que se trata de uma igreja dentro da Igreja Católica.

Também Clodovis Boff (2000, p. 46) considera como uma das deficiências da RCC a "tendência ao paralelismo pastoral", afirmando que "a RCC pena em se inserir na caminhada da Igreja local. É criticada por seu "fechamento' sobre si mesma e suas atividades próprias". No entanto, esse autor chama atenção para a existência de um espaço legítimo na estrutura da Igreja Católica para esse tipo de autonomia ou aparente paralelismo da RCC. De forma similar a institutos religiosos, a RCC estaria adotando o "dispositivo 
canônico da 'isenção' e da obediência particular ao Papa", podendo dessa forma privilegiar "a ligação com o Papa", ao invés da inserção na Igreja local (Boff, 2000, p. 46). Assim, como foi dito, somente se pode entender a organização do MRCC dentro do contexto da Igreja mais ampla que o inclui e conforma.

No entanto, é interessante notar que apesar de toda essa constatação e mesmo análise crítica à autonomia e paralelismo do MRCC dentro da Igreja Católica apontada pelos autores acima, há pesquisadores, como Reginaldo Prandi (1997) e Júlia Miranda (1999), que consideram o movimento muito vinculado e dependente da estrutura eclesiástica da Igreja. Reginaldo Prandi (1997, p. 33) observa que "a RCC adotou desde seu início vigorosa estratégia de aderência à estrutura eclesiástica, conquistando paróquias e bispados". Como exemplo dessa aderência, Prandi cita o caso, já no início da RCC nos EUA, de leigos carismáticos que receberam do bispado a incumbência de tomar conta de uma paróquia. $\mathrm{O}$ movimento surgiu assim para atuar no interior das paróquias. Já Júlia Miranda questiona a proposta e poder renovador do MRCC por sua preocupação em seguir as orientações dos bispos e obedecer incondicionalmente ao Papa. Essa autora se pergunta "trata-se aqui de uma renovação que permanece presa à organização existente e à sua estrutura?" Além disso, essa autora chama atenção para a grande preocupação "com a instauração de normas de conduta e de formas de comportamento (...)" nas comunidades de aliança e especialmente nas de vida (Miranda, 1999, p. 53). Tanto para Júlia Miranda como para Reginaldo Prandi, a organização do MRCC tem levado a maior integração numa organização eclesiástica não renovada. Para a primeira autora essa estruturação é maior nas comunidades de vida:

Penso que, nos grupos de oração e louvor, estamos face a comunidades espontâneas. Não obstante, a Renovação Carismática parece ter, por outro lado, abandonado essa característica de "sopro pentecostal" no seio de uma Igreja enrijecida pelo tempo e pelos compromissos, quando observamos o cotidiano das comunidades de aliança e de vida. Nelas, a estrutura parece sufocar a espontaneidade. Esta última pouco se diferencia das ordens religiosas tradicionais (Miranda, 1999, p. 152).

$\mathrm{O}$ argumento do presente artigo integra as duas posições aparentemente contraditórias do primeiro e segundo conjunto de autores. Argumenta-se que justamente por adquirir um certo paralelismo e autonomia organizacional, a RCC pôde se integrar à estrutura mais ampla da Igreja. Embora ofereça dispositivos para criação de organizações religiosas relativamente autônomas, a Igreja procura manter seus grupos internos dentro de certo controle. Documentos, como, por exemplo, o já referido anteriormente da CNBB 
sobre o MRCC, cobram uma conformação a regras claramente definidas. ${ }^{11}$ Apesar de oficialmente se cobrar que se evite paralelismo, esse parece ser aceito como necessário.

Um desconforto com o paralelismo é também sentido pelos líderes da RCC. Esses líderes querem de alguma forma superar esse paralelismo porque o projeto da Renovação é transformar a Igreja e não ser um "movimento religioso" a mais, que vive sua fé e experiências separadamente do resto da Igreja, como ficou claro nas declarações já citadas. Ser uma estrutura paralela não é o projeto do RCC, mas um resultado de sua impossibilidade de integração. Como suas propostas não são aceitas em determinados contextos, ao invés de forçá-los a sair, a organização da Igreja oferece possibilidades para a sobrevivência desse projeto com relativa autonomia. Além do mais, a dimensão que alcançou, a complexidade de sua estrutura e o apoio por uma parte do clero ampliam a capacidade da Renovação em ser relativamente autônoma.

Desta forma, observa-se que na prática organizacional da própria Igreja Católica há espaço para o surgimento de uma subestrutura organizacional que parece ser paralela em algumas instâncias, e não o ser em outras. Essa seria uma dinâmica organizacional que ajuda a manter a pluralidade dentro das fronteiras institucionais mais ampla. Graças a esses dispositivos, propostas de críticas ao status quo eclesial que cobravam transformação de toda Igreja não levaram necessariamente a rupturas radicais. Reavivamentos, como o pentecostal, que geraram dissidências e criação de novas seitas quando ocorreram em outro tipo de organização, deram origem na Igreja Católica ao MRCC, que reforça a tradição e estrutura da Igreja, embora traga elementos renovadores. ${ }^{12}$ A criação de uma subestrutura organizacio

\footnotetext{
${ }^{11}$ Sobre o controle que a hierarquia mais ampla exerce sobre a Igreja, vários autores chamaram atenção para a diminuição da atitude ecumênica do movimento quando da sua maior institucionalização e integração à estrutura da Igreja (ver, por exemplo, Machado, 1994 e Cohen, 1990). Machado e Fernandes (2000) também chamam atenção para o crescimento da presença de lideranças sacerdotais na RCC no Brasil.

${ }^{12}$ Esse caráter duplo da RCC foi observado e analisado por Camurça (2001).
} 
nal dentro da Igreja mais ampla permite que se "saia" da Igreja ficando dentro dela, se proponha mudá-la e ao mesmo tempo se ajude a mantê-la.

\section{Referências}

BOFF, Clodovis. Carismáticos e libertadores na Igreja. REB, v. 60, n. 287, p. 36-53, 2000.

CAMURÇA, Marcelo. Renovação Carismática Católica: entre tradição e modernidade Revista Rhema, v. 7, n. 25, 2001.

CARRANZA, Brenda. Renovação Carismática: origens, mudanças, tendências. Aparecida: Editora Santuário, 2000.

COHEN, Martine. Les renoveaux catholique et juif en France. In: F. CHAMPION e D. HERVIEU-LEGER (Org.). De l'émotion en religion; renouveaux et traditions. Paris: Centurion, 1990. p. 123-169.

La regulation catholique dês pratiques pentecôtistes au sein du Renouveau Charismatique Français. In: George BERTIN e Marie Claude ROSSEAU (Org.). Pentêcote: de l' inteme au social. Nantes: Siloë- Université Catholique de l'Ouest, 1997. p. 131-150.

FERNANDES, Sílvia R. Alves. Movimento Carismático Católico: ethos comum e antagônico em camadas populares no Rio de Janeiro. Revista Universidade Rural, Rio de Janeiro. Série Ciências Humanas, v. 18, n. 1, 1996.

HERVIEU-LÉGER, D. Le Pélerin et le Converti. Paris: Flammarion, 1996.

MACHADO, Maria das Dores C. Carismáticos e pentecostais: adesão religiosa na esfera familiar. Campinas: Editores Autores Associados, 1996.

MACHADO, Maria das Dores C. e Sílvia A. FERNANDES. Carismáticos e pentecostais: a dimensão religiosa dos movimentos revivalistas. Magis: Cadernos de Fé e Cultura, Rio de Janeiro, v. 37, p. 151-168, 2000. (Publicado pelo Centro Loyola de Fé e Cultura PUC)

MARIANO, Ricardo. Análise Sociológica do Crescimento Pentecostal no Brasil. Tese de Doutorado em Sociologia apresentada no Programa de Pós-Graduação do Depto. de Sociologia na Universidade de São Paulo, 2001.

MARIZ, Cecília.L. e Maria das Dores C. MACHADO. Sincretismo e trânsito teligioso: comparando carismáticos e pentecostais. Comunicações do Iser, Rio de Janeiro, v. 13, n. 45, p. 24-34, 1994.

MARIZ, Cecília L. Pentecostalismo, Renovação Carismática e Comunidade de Base: uma análise comparada. Cadernos do Ceris. v. 1, n. 2, p. 11-42 e 69-73, 2001.

MARX, Karl. A questão judaica. Rio de Janeiro: Ed Moraes, s. d.

MIRANDA, Júlia. Carisma, sociedade e política: novas linguagens do religioso no político. Rio de Janeiro: Jorge Zahar, 1999.

OLIVEIRA, Eliane Martins. O novo canto da Canção Nova. Dissertação de Mestrado Programa de Pós-Graduação em Ciências Sociais (Ppcis), Uerj, Rio de Janeiro, 2003.

OLIVEIRA, Pedro A. Ribeiro de. CE: unidade estruturante. In: Clodovis BOFF et al. Comunidades de Base em questão. São Paulo: Paulinas, 1997.

ORO, Ari. Avanço pentecostal e reação católica. Petrópolis: Vozes, 1996. 
PRANDI, Reginaldo. Um sopro do Espírito. São Paulo: Edusp, 1997.

SANTOS, Carlos James dos. Análise de conjuntura religioso-eclesial. Cadernos do Ibrades. v. 40, p. 19-43, 1996.

SOUZA, Luiz Alberto Gómez de. As CEBs vão bem, obrigado. Revista Eclesiástica Brasileira (REB). v. 60 , n. 287 , p. $55-110,2000$.

STACCONE, G. Filosofia da religião. Petrópolis: Vozes, 1989.

WEBER, Max. Economia e sociedade. Brasília: Ed. UnB, 1991. 